\title{
Filosofía: perplejidad, búsqueda y compromiso. Una aproximación a la filosofía y al conocimiento desde la Apología de Sócrates
}

\author{
María Elena Radici*
}

\begin{abstract}
Sólo hay un camino de humanización, aunque transitable de muchas maneras, tanto individual como sociocultural: el de la maduración de la propia conciencia y libertad, asumiendo la propia condición, con sus posibilidades y sus límites, aceptando la separatidad y la incertidumbre, así como yendo a nuevas relaciones humanizantes -implica que sean respetuosas de la autonomía individual- con nosotros mismos, los demás y el entorno. Desde ese trasfondo de una racionalidad sana es posible, y necesario, articular un sentido para lo que es una existencia "abierta”, esencialmente problemática, que requiere dar respuestas al por qué y para qué vivir.

José Antonio Pérez Tapias, Filosofía y crítica de la cultura, Trotta, 1995
\end{abstract}

Tener que bosquejar hoy un perfil del filósofo no parece ser una tarea central de la filosofía. La problemática realidad actual exige más bien una reflexión esclarecedora y comprometida acerca de los problemas que afectan al hombre y su entorno, es decir, a la condición humana y a las posibilidades de una supervivencia verdaderamente humana.

Sin embargo, retrotraernos al filósofo vivo, al filósofo que reflexiona a partir de la circunstancia vital, tal como muestra Platón a Sócrates en la Apología, puede ser un camino para repensar y redescubrir el hilo común que enlaza un quehacer del hombre que no ha perdido vigencia: el quehacer filosófico.

\section{Filosofía como sabiduría: la tarea del filósofo}

Referirse al filósofo supone siempre tener en cuenta la clásica etimología del término griego filosofía que señala, en primer lugar, el amor a la sabiduría. Qué es la sabiduría, en cambio, no está tan claro después de veinticinco siglos de Filosofía, filósofos y filosofías. Definirla exigiría un largo camino de clarificación del lenguaje filosófico, al modo del primer Wittgenstein, y es posible que al final nos encontremos como al inicio: con una gran diversidad de respuestas, en relación con la perspectiva filosófica adoptada.

Consideramos a Sócrates el iniciador de la filosofía, o más bien el primer filósofo, el amante de la sabiduría. ¿Qué tiene de peculiar Sócrates que lo diferencia de los antiguos "indagadores de la naturaleza" que buscaban el arjé de todas las cosas? Es el mismo Sócrates quien nos orienta en la respuesta a lo largo de la Apología. Si el filósofo es el que busca la verdad es justamente porque no la tiene. El conocer no es sinónimo de sabiduría, ni siquiera cuando es conocimiento (o conjetura) de las causas físicas de "todas las cosas".

La sabiduría, por tanto, no va a consistir en acumulación de conocimientos, ya que todo saber está limitado en el hombre por sus propias posibilidades de conocimiento. "Sólo el dios es el verdadero sabio". ${ }^{1}$

Pero el interrogante del que parte Sócrates es la misteriosa afirmación del oráculo de Delfos que lo considera el hombre más sabio del mundo. ¿Cómo llegar a comprender lo que quiere decir el dios si Sócrates mismo no se considera sabio?

\footnotetext{
* Profesora Antropología Filosófica (UNNE) - e-mail: hrodolfo@yahoo.com.ar

${ }^{1}$ Platón. Apología de Sócrates, Anotaciones: Arturo Marasso, Edit. Estrada, Bs. As., 1957, p. 14.
} 
Sócrates señala que "son muchos los que creen saber algo, aunque no sepan nada o casi nada" ${ }^{2}$, es decir, son muchos los que se creen sabios, pero es necesario ver en qué basan esta creencia. Después de interrogar detenidamente (examinar) a políticos, poetas y artesanos comprueba que ninguno de ellos resiste la interrogación, quedando en evidencia que saben muchas cosas, pero este saber "les ocultaba el verdadero saber"3.

Si la sabiduría no es, por tanto, saber hacer cosas a la manera de la tekné, ni componer bellos poemas -que parten de la inspiración y no de la ciencia-, ni saber acerca de la "cosa pública”, entonces el oráculo se refiere, seguramente, a algo diferente, a algo no tan visible como la acumulación de riquezas por el dominio de un oficio o el mantenimiento de cargos "honrosos" al servicio de la "república” (polis), modos de vida considerados sabios por la mayoría. Llega así Sócrates a descubrir que posee la sa-

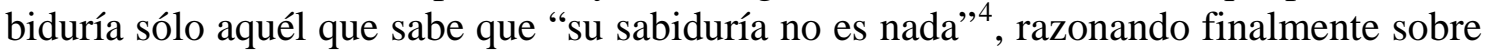
la diferencia que lo hace sabio: "puede muy bien suceder, que ni él ni yo sepamos nada de lo que es bello y de lo que es bueno; pero hay esta diferencia, que él cree saberlo aunque no sepa nada, y yo, no sabiendo nada, creo no saber". 5

El saber que no se sabe será el descubrimiento central de la Apología, ya que este saber es el que permite, por una parte, afirmar que Sócrates es sabio en oposición a los "falsos" sabios y, por otra parte, indica el camino a seguir.

De este modo el "conócete a ti mismo" del oráculo de Delfos va a cobrar fuerza de obligación para todo aquél que quiera emprender el camino de la sabiduría. En reiteradas oportunidades señalará Sócrates que no hay mayor bien que dedicarse al "cuidado del alma y su perfeccionamiento"-es decir, al logro de la virtud-, mientras que creer ser lo que no se es, o dedicarse a la acumulación de riquezas, es apartarse del camino de la sabiduría. Todos lo bienes, privados o públicos, nacen de la virtud, entendida como "hacer tu alma tan buena como pueda serlo" ${ }^{6}$, desarrollando las cualidades propias del hombre y del ciudadano.

Esta es la razón por la que Sócrates, aun frente a la muerte, no puede aceptar callarse, ya que hacerlo significaría traicionar la voz (vocación filosófica) que lo guía. El "amor a los demás" lo mueve a despertar las conciencias y exhortar a la virtud, a riesgo de ganarse odios y antipatías. Llamar la atención sobre la verdadera ignorancia, ignorancia acerca del propio no-saber e ignorancia acerca de la muerte, es la tarea de un filósofo comprometido con su vocación.

El camino ya lo conocemos: interrogar es examinar, pero no va a consistir solamente en señalar los errores, sino que fundamentalmente es diálogo clarificador en la búsqueda de la verdad que habita en cada hombre.

Pero el filósofo es, además, -y esto muestra claramente el pensamiento ético de Sócrates-, un hombre de honor y de valor, que se compromete con lo que considera justo, y que defiende, sin temor a la muerte, la justicia frente a las injusticias. El sabio, en este sentido, debe mostrar claramente la coherencia entre su modo de obrar y su modo de pensar, por lo cual Sócrates puede ponerse a sí mismo como ejemplo válido.

\section{Filosofía y conocimiento}

Aproximarnos a una imagen del filósofo siguiendo a Sócrates significa, al mismo tiempo, acercarnos a una concepción del conocimiento.

\footnotetext{
2 Ibid., p. 15

${ }^{3}$ Ibid., p. 14

${ }^{4}$ Ibid., p. 15

${ }^{5}$ Ibid., p. 12

${ }^{6}$ Ibid., p. 29
} 
El primer saber que ha de alcanzar el hombre, saber indispensable y condición de todo otro saber es la "conciencia de no-saber". ¿Cómo se llega a este no-saber? Ya hemos señalado que uno de los caminos posibles es el examinarse, ya que "una vida sin examen no merece ser vivida"7. Sólo estudiándose a sí mismo, descubriendo la propia ignorancia, se encuentra el hombre en disposición de buscar la verdad y la virtud. Pero también es importante el dejarse examinar por los otros.

Justamente ésta es la tarea del filósofo: examinarse y examinar a los demás, con el objetivo de conocerse a sí mismo, y de ayudar a los demás a conocerse, a descubrir que quizás no se sabe lo que se creía saber, pero se sabe lo que no se creía saber. Ironía y mayéutica, a través de la interrogación, son los pasos del método socrático y constituyen la "habilidad" del verdadero sabio. Ni la habilidad oratoria ni el uso inteligente de argumentos persuasivos (propios de los sofistas, que deslumbraban a los padres preocupados por la educación de sus hijos) son considerados válidos para Sócrates: son inmorales, en la medida en que pueden convertir en malas las buenas causas, y en buenas las malas, y pueden convencer haciendo ver como verdadero lo que es falso y erróneo.

Ahora bien, ¿qué es la verdad para Sócrates? En primer lugar, la verdad es la propia realidad: el hombre es no sólo un ser limitado sino también mortal, lo cual va acompañado de inseguridad e incertidumbre. Ni los cargos honrosos, ni la riqueza y tampoco el favor de los jueces, pueden dar seguridad al hombre: nadie puede escapar de la muerte; el destino del hombre es la virtud, conservar el honor que ni siquiera la muerte puede quitar. Por eso el sabio mantiene la serenidad ante estas realidades ya que, a diferencia de los falsos sabios, sabe que él puede elegir la virtud y la coherencia con las propias convicciones aunque no le sea dado evitar sufrir injusticias. ${ }^{8}$

Aunque hablar de la teoría del conocimiento en Sócrates requeriría adentrarse en otras obras, además de la Apología, considero que, no obstante, sobre el trasfondo de ésta resalta que, para Sócrates no existe sabiduría sin virtud: la sabiduría se alcanza a partir del conocimiento de sí mismo (humildad), del deseo de verdad que esta "ignorancia” suscita, de la confianza en alcanzar de algún modo esta verdad, y en especial, del reconocimiento y la necesidad de obedecer al daimon personal, "voz" que no deja en paz a Sócrates en los momentos en que puede llegar a apartarse de la justicia y la piedad. Pero tampoco hay virtud sin sabiduría: ¿cómo regirse por la verdad, la belleza y la justicia si no hay un "alumbramiento" acerca de lo que es verdadero, bueno, bello o justo?, (por eso la virtud no puede enseñarse aunque se puede apartar a los jóvenes del camino errado de las riquezas)

Vemos entonces que el conocimiento, para Sócrates, está imbuido de actitudes no hay conocimiento que no implique un modo de obrar-. El mayor obstáculo para la virtud es el "creer que se sabe”, fundamentalmente porque está cerrado a toda posibilidad de conocimiento y de cambio. (Aunque a nivel de lo social también aparezcan "obstáculos” como el descrédito de la pobreza y del desprendimiento a favor de la reflexión).

Partiendo de las afirmaciones anteriores, se pueden plantear diversos interrogantes: ¿Está Sócrates en el camino “místico”? Quizás sea una interpretación posible, si consideramos que todo camino místico supone un no saber: "quedéme no sabiendo, toda ciencia trascendiendo" (San Juan de la Cruz) y que Sócrates es guiado por una "voz interior". La diferencia estriba en que el no-saber del místico forma parte de la experiencia de encuentro con el Otro, experiencia tan intransferible, vital, "inefable” y abarcado-

\footnotetext{
${ }^{7}$ Ibid., p. 46

${ }^{8}$ Ibid., p. 34-35
} 
ra que implica el no-saber como no-conciencia de sí y del mundo. En este caso podría decirse que el no-saber está al final del camino, no al comienzo, como en Sócrates. Por otra parte, en Sócrates hay clara conciencia del no-saber.

Respecto a la relación mística-filosofía, encontramos que para el primer Wittgenstein, la filosofía, en tanto actividad terapéutica de auto anulación (disolución de los problemas), es camino para mostrar lo místico. "Y esta mostración es, en el fondo, una nueva forma de ver, porque la filosofía deja todo como está. Es exclusivamente descriptiva”. ${ }^{9} \mathrm{Al}$ abandonar la especulación aparecerá la "justa visión del mundo". Lo místico es lo que no puede ser dicho, sino sólo "mostrado", a riesgo de caer en proposiciones sinsentido, tal como ocurre con la filosofía cuando lo intenta. Pero mientras Wittgenstein dirige su mirada hacia los problemas del lenguaje "metafísico" derivando en la necesidad de la disolución de los problemas filosóficos para arribar al silencio, en Sócrates el no-saber es sinónimo de deseo de saber, de búsqueda permanente.

En segundo lugar, referirnos a la incertidumbre y a la inseguridad quizás signifique dar un salto histórico, ya que es el existencialismo el que más ha ahondado en estos estados anímicos y el que ha centrado sus elaboraciones en la única certeza del hombre, la muerte (el "ser-para la muerte", como dice Heidegger, el ser "moriturus", para J. Marías). La inseguridad, para E. Fromm, es "el precio que el hombre paga por su conciencia” ${ }^{10}$ y por su libertad. La disminución del determinismo instintivo y del desarrollo en tamaño y complejidad del cerebro constituyen las "condiciones de la existencia humana”, las condiciones de la conciencia y la libertad que lo conducen a la incertidumbre, por lo cual el hombre debe fabricar marcos de devoción (nexos emocionales) y marcos de orientación (imágenes coherentes del mundo) no sólo para sobrevivir, sino aun más para trans-sobrevivir (comprender el sentido de la vida humana). ${ }^{11}$

En tercer lugar, ¿podemos señalar límites para el conocimiento que postula Sócrates? ¿Se pueden alcanzar la verdad y la belleza? Sócrates afirmaba:”yo no digo más que la verdad”, es decir, "no miento", pero esta afirmación se distancia de lo que hoy se suele entender como verdad científica: comprobable, verificable, adecuada a los hechos (certeza objetiva).

Popper considera que Sócrates inaugura el falibilismo y la idea de búsqueda de la verdad como progresivo acercamiento. Al aplicar la ironía es posible "comprobar" si realmente es verdadero lo que afirmamos como verdadero, es decir, "falsar", y al utilizar el diálogo se produce el acercamiento a la verdad. Popper deriva de la actitud de Sócrates tres principios éticos que son básicos para toda discusión racional, entre los cuales destaco el tercero, llamado "principio de aproximación a la verdad: en una discusión que evite los ataques personales, casi siempre podemos acercarnos a la verdad"12. La imposibilidad de alcanzar "verdad" sin diálogo es una de las coincidencias de las filosofías que parten del Lenguaje actualmente.

El problema del conocimiento ha sido uno de los problemas centrales de la filosofía, sobre todo en la Modernidad, dando lugar a numerosas “dicotomías” y discusiones relacionadas con la perspectiva general adoptada. El problema reside en que se intenta explicar aquello en lo que se está implicado, se cuestionan los “anteojos con que se mira” pero mirando a través de los mismos.

\footnotetext{
${ }^{9}$ Vicente Arregui, Jorge. Acción y sentido en Wittgenstein, p.63

${ }^{10}$ Fromm, Erich. La revolución de la esperanza, rev. Omar Pérez, F.C.E., México, 1970, p.68

${ }^{11}$ Fromm, op. cit., p. 68-78

${ }^{12}$ Popper, Karl. “Tolerancia y responsabilidad intelectual”, en En busca de un mundo mejor, trad. Vigil

Rubio J., Paidos, Barcelona, 1996, p. 255
} 
Así, al preguntar por el origen, mientras los empiristas señalan que "sólo se conoce por los sentidos" (Hume), los racionalistas dan preeminencia y exclusividad a la razón (Descartes). Podríamos plantear el problema del conocimiento a modo de interrogación: ¿la razón o los sentidos?, ¿ideas innatas o “tabula rasa”?, ¿Sujeto trascendental, categorías del entendimiento y caos de sensaciones, o mundo lógico y ordenado cuya copia o imagen se reproduce en la mente? ¿Construcción o revelación? ¿Interpretación o espejo? Y aún más: ¿Posibilidad de alcanzar la verdad que se oculta (y se desoculta) o imposibilidad de conocer el nóumeno?, ¿conceptualización, metáfora o poesía, racionalidad-objetividad o subjetividad-emocionalidad? ¿Lenguaje que significa y señala (semanticidad) o lenguaje-uso y acción (pragmaticidad)?

¿Cómo integrar la multiplicidad de perspectivas acerca del conocimiento, perspectivas que suponen diversidad de ideas o imágenes de hombre, a veces totalmente excluyentes? Quizás una de las propuestas más viables y adecuadas sea la de Edgar Morin, que nos introduce en la consideración de un "pensamiento complejo" capaz de integrar lo que se nos presenta como opuesto. Si nos remitimos a Sócrates, esta tarea es también una búsqueda, un camino de indagación.

\section{Sentido de la filosofía hoy: una visión más personal}

¿Sigue teniendo sentido el quehacer filosófico en un mundo empapado no sólo de tecnologías sino de una concepción cientificista? ¿Cómo entenderla hoy?

Realizar un trabajo de indagación acerca de las significaciones que ha ido adquiriendo a lo largo de los siglos la palabra "filosofía”, significaciones conectadas primordialmente con diversas concepciones del hombre y del mundo posiblemente no nos dé la respuesta. Quizás, para sintetizar, cabría citar a Ortega, cuando afirma: "la misma palabra filosofía arrastra milenariamente este estigma de frivolidad: significa sólo la afición a saber". ${ }^{13}$

Por otra parte, reducir el quehacer filosófico a una terapéutica que "disuelve los problemas” para superar la perplejidad que proviene de lo confuso del lenguaje filosófico (ambigüedad, ambivalencia) tal como lo plantea el primer Wittgenstein ¿no significa cerrar el campo de la filosofía? Y esto sin dejar de pensar que el análisis lógico se sigue mostrando como necesario para toda posibilidad de diálogo que lleve al entendimiento, para que el lenguaje no sea "barrera" que impida, sino camino que permita la comunicación.

Pienso que hoy la filosofía debería ser, sobre todo, reflexión sobre los ámbitos del hacer y del obrar humano. A la humanidad no le basta conocer y hacer (fabricar, crear) sólo para una mera supervivencia de la especie -a pesar y en contra de un darwinismo social legitimador de este fin--, sino que busca encontrar caminos, medios para lograr una supervivencia verdaderamente humana. ¿En qué medida la filosofía contribuye actualmente a una mayor conciencia de los problemas que afectan al hombre, a cada uno y a la humanidad? ¿En qué medida lo económico, que origina desigualdades y exclusiones, es más fuerte que cualquier pensamiento y que cualquier acción a favor de los derechos del hombre? ¿En qué medida la denuncia y los llamados de atención provienen de todos los ámbitos, pero menos de la filosofía?

La vigencia del "no tener más remedio que razonar ante la inexorable circunstancia” ${ }^{14}$ posiblemente señale la tarea más urgente de la filosofía: ¿puede la filosofía es-

\footnotetext{
${ }^{13}$ Ortega y Gasset, J. Obras Completas, Alianza Editorial.Revista de Occidente, Madrid, 1983, Tomo V p.84 (En torno a Galileo).

${ }^{14}$ Ibid, p. 67
} 
tar ajena a la vida? Pero entonces nos preguntamos qué significa hablar de vida, si nos dirigimos a la vida en general o estamos tratando de delimitar de algún modo la vida humana.

Si tratamos de pensar al hombre nos damos cuenta de que no podemos verlo sino en relación: relación con el mundo (ser-en el-mundo) y con los otros (Mit-Dasein). Como señala H. Mead, el hombre se caracteriza por ser con otro ya desde el vamos. Pensar al hombre significa reconocer su complejidad en tanto ser biológico y sociocultural (económico, político, científico, técnico, lingüístico). Significa también reconocer, siguiendo a E. Fromm, las "múltiples posibilidades de ser hombre": homo faber, homo sapiens, homo amans, homo esperans, homo ludens..., "manifestaciones de lo humano (que) no son la respuesta a lo que significa ser hombre, sino (que) responden a la pregunta: ¿qué tan diferentes podemos ser $y$, sin embargo, ser hombres? ${ }^{15}$

En este sentido, preguntarse por la vida humana significa, de algún modo, que no se puede pensar al hombre sin tener en cuenta lo que hoy, en especial, lo condiciona, lo afecta, lo deshumaniza. Y reflexionar desde los problemas ecológicos, educativos, sociales, políticos, tecnocientíficos es hacerlo desde la filosofía práctica, más específicamente desde la Ética.

Ante los avances científico-técnicos, por ejemplo, ¿no nos sentimos obligados a interrogar acerca de las consecuencias que tienen para el hombre? Ante el fenómeno del pluralismo ¿no cabría examinar si ciertas prácticas sociales no constituyen una agresión a la condición humana? Pensemos en la discriminación de niños y ancianos, en la discriminación y violencia contra la mujer, en los diversos modos de dominación encubiertos tras determinadas pautas culturales, en los fenómenos de la desigualdad y la exclusión legitimados por “juegos de mercado”. ¿Qué significado, por ejemplo, adquiere la tolerancia?

Mientras desde distintos "bandos" se acusa de etnocentristas a representantes del pensamiento europeo occidental -que afirma verdades y defiende "certezas" universales-, tanto como a liberales -que consideran la propia tradición como modelo de toda práctica socio-cultural-, se olvida que lo que interesa a la filosofía es en realidad ser capaz de encontrar a través del diálogo los mínimos comunes que protejan al individuo, la comunidad y la sociedad humana en su conjunto, no sólo por la tolerancia como respeto a la diferencia, sino por un consenso que evite "tolerar" aquello que destruye al hombre, llamémoslo "crueldad” (Rorty) o cualquier otra forma de pensamiento y acción que lo trate como medio y no como fin, que no lo reconozca en su condición única y esencialmente humana.

Además, considero que hay otro aspecto que no puede ser dejado de lado: ¿puede realizarse la reflexión filosófica hoy como teoría, como pensamiento "desasido", no comprometido? Pienso, por ejemplo, que sólo la convicción acerca de la necesidad y exigibilidad de la tolerancia va a conducir a la efectivización de la misma, así como sólo el reconocimiento de los derechos del hombre puede llevar a buscar los medios más adecuados para que se concreten. Podría decirse que la actitud filosófica vital de Sócrates, en tanto afirma "no poder callar", no ha perdido vigencia.

Intentar aclarar de dónde parte el reconocimiento de lo humano, si de la consideración de la autonomía al modo kantiano, o de la afirmación de la igualdad y la libertad, o del factum del lenguaje -que es sólo propio del hombre y lo muestra como ser dialógico e intersubjetivo-, implica una discusión aparte. Personalmente creo que sería posible

\footnotetext{
${ }^{15}$ Fromm, op. cit., p.67
} 
encontrar más coincidencias filosóficas acerca del hombre si el diálogo estuviera orientado hacia un mínimo de universalidad, más que a señalar disyunciones.

Por último, deseo destacar dos pensamientos a modo de conjeturas:

1. que quizás sea la perplejidad del hombre actual la que oriente al filósofo, perplejidad ante la deshumanización que se da no sólo en las prácticas, sino en los pensamientos (o ideologías) que las sostienen,

2. que una filosofía que frivoliza las convicciones para no entrar en conflictos (Rorty) olvida que hay certezas que son el resultado de la historia humana misma y constituyen un mínimo común insoslayable e innegable (A. Cortina), ya que sólo a partir del mantenimiento del mismo podrán darse lo diversos modos de vida "feliz" sin que ninguno de ellos pretenda convertirse en único.

Por otra parte, que no basta actualmente una filosofía que solamente piense la tolerancia que puede derivar en indiferencia, ya que "respetar" actualmente es "hacerse responsable" de la concreción de las condiciones que hacen posible la libertad (y el pluralismo), y por tanto es necesario también pensar la necesidad y los fundamentos de la solidaridad, para que se dé una verdadera participación de todos en los bienes culturales y materiales de la sociedad y de la humanidad.

\section{Conclusión}

La figura de Sócrates sigue siendo “ejemplar” por lo actual: no se filosofa para obtener éxitos ni honores, ni siquiera para conocer las causas de todas las cosas: filosofía es quehacer vital. La serenidad ante la injusticia y la muerte provienen, ante todo de la conciencia de la propia coherencia: vivir de acuerdo con lo que se estima justo y verdadero (virtud). La verdad, entonces, puede pertenecer y no pertenecer a un solo hombre en particular. Por eso el diálogo es camino.

Pero el hombre no puede vivir en la incertidumbre y en la duda: el no-saber es solamente la instancia inicial y recurrente que muestra la necesidad de "marcos" para orientarnos y vincularnos, de un saber siempre abierto y que incluye a los demás.

$\mathrm{Si}$, como dice el lema latino: non scholae, sed vitam discimus (aprendemos para la vida), también el filosofar cobra sentido en esta dirección. "No es, pues, la vida para la inteligencia, la ciencia o la cultura, sino al revés: la inteligencia, la ciencia, la cultura, no tienen más realidad que la que les corresponda como utensilios para la vida"16

Ahora bien, parece que la filosofía no puede ya hacerse cargo de los problemas si no es a través del diálogo con aquello mismo que cuestiona, es decir, no puede hacerse cargo de una imagen humanizada del hombre si no integra los aportes de las ciencias en general, la psicología, las investigaciones sociales, históricas, artísticas y religiosas, es decir de todo lo que atañe al hombre, porque lo crea, lo produce y lo constituye, comprendiendo a su vez que sólo ella es capaz de mostrar lo inacabado del hombre, su radical apertura y su condición de "amante de la sabiduría", "buscador incansable de sentido”.

\footnotetext{
${ }^{16}$ Ortega y Gasset, op. cit. p. 88
} 